\title{
Comparison of clinical outcome after first-line platinum-based chemotherapy in different types of KRAS mutated advanced non-small-cell lung cancer
}

Citation for published version (APA):

Mellema, W. W., Masen-Poos, L., Smit, E. F., Hendriks, L. E. L., Aerts, J. G., Termeer, A., Goosens, M. J., Smit, H. J. M., van den Heuvel, M. M., van der Wekken, A. J., Herder, G. J. M., Krouwels, F. H., Stigt, J. A., van den Borne, B. E. E. M., Haitjema, T. J., Staal-Van den Brekel, A. J., van Heemst, R. C., Pouw, E., \& Dingemans, A-M. C. (2015). Comparison of clinical outcome after first-line platinum-based chemotherapy in different types of KRAS mutated advanced non-small-cell lung cancer. Lung Cancer, 90(2), 249-254. https://doi.org/10.1016/j.lungcan.2015.09.012

Document status and date:

Published: 01/11/2015

DOI:

10.1016/j.lungcan.2015.09.012

Document Version:

Publisher's PDF, also known as Version of record

Document license:

Taverne

Please check the document version of this publication:

- A submitted manuscript is the version of the article upon submission and before peer-review. There can be important differences between the submitted version and the official published version of record.

People interested in the research are advised to contact the author for the final version of the publication, or visit the DOI to the publisher's website.

- The final author version and the galley proof are versions of the publication after peer review.

- The final published version features the final layout of the paper including the volume, issue and page numbers.

Link to publication

\footnotetext{
General rights rights.

- You may freely distribute the URL identifying the publication in the public portal. please follow below link for the End User Agreement:

www.umlib.nl/taverne-license

Take down policy

If you believe that this document breaches copyright please contact us at:

repository@maastrichtuniversity.nl

providing details and we will investigate your claim.
}

Copyright and moral rights for the publications made accessible in the public portal are retained by the authors and/or other copyright owners and it is a condition of accessing publications that users recognise and abide by the legal requirements associated with these

- Users may download and print one copy of any publication from the public portal for the purpose of private study or research.

- You may not further distribute the material or use it for any profit-making activity or commercial gain

If the publication is distributed under the terms of Article $25 \mathrm{fa}$ of the Dutch Copyright Act, indicated by the "Taverne" license above, 


\title{
Comparison of clinical outcome after first-line platinum-based chemotherapy in different types of KRAS mutated advanced non-small-cell lung cancer
}

\author{
Wouter W. Mellema ${ }^{a}$, Lucie Masen-Poos ${ }^{b}$, Egbert F. Smit ${ }^{a}{ }^{*}$, Lizza E.L. Hendriks $^{c}$, \\ Joachim G. Aerts ${ }^{\mathrm{d}}$, Arien Termeer ${ }^{\mathrm{e}}$, Martijn J. Goosens ${ }^{\mathrm{f}}$, Hans J.M. Smit ${ }^{\mathrm{g}}$, \\ Michel M. van den Heuvel ${ }^{\mathrm{h}}$, Anthonie J. van der Wekken ${ }^{\mathrm{i}}$, Gerarda J.M. Herder ${ }^{\mathrm{j}}$, \\ Frans H. Krouwels ${ }^{\mathrm{k}}$, Jos A. Stigt ${ }^{1}$, Ben E.E.M. van den Borne ${ }^{\mathrm{m}}$, Tjeerd J. Haitjema ${ }^{\mathrm{n}}$, \\ Agnes J. Staal-Van den Brekel ${ }^{ }$, Robbert C. van Heemst ${ }^{\mathrm{p}}$, Ellen Pouw ${ }^{\mathrm{q}}$, \\ Anne-Marie C. Dingemans ${ }^{c}$
}

\footnotetext{
a Department of Pulmonary Diseases, VU University Medical Center, Amsterdam, Netherlands

${ }^{\mathrm{b}}$ Department of Pulmonary Diseases, Jeroen Bosch hospital's-Hertogenbosch, Netherlands

c Department of Pulmonary Diseases, Maastricht University Medical Center, Maastricht, Netherlands

d Department of Pulmonary Diseases, Amphia hospital, Breda, Netherlands

e Department of Pulmonary Diseases, Canisius Wilhemina hospital, Nijmegen, Netherlands

${ }^{\mathrm{f}}$ Department of Pulmonary Diseases, Gelre hospital, Zutphen, Netherlands

${ }^{g}$ Department of Pulmonary Diseases, Rijnstate hospital, Arnhem, Netherlands

h Department of Thoracic Oncology, NKI-AvL, Amsterdam, Netherlands

i Department of Pulmonary Diseases, University of Groningen, University Medical Center Groningen, Groningen, Netherlands

${ }^{j}$ Department of Pulmonary Diseases, St Antonius hospital, Nieuwegein, Netherlands

${ }^{\mathrm{k}}$ Department of Pulmonary Diseases, Spaarne hospital, Hoofddorp, Netherlands

${ }^{1}$ Department of Pulmonary Diseases, Isala clinics, Zwolle, Netherlands

m Department of Pulmonary Diseases, Catharina hospital, Eindhoven, Netherlands

${ }^{n}$ Department of Pulmonary Diseases, Alkmaar Medical Center, Alkmaar, Netherlands

o Department of Pulmonary Diseases, Ziekenhuis groep Twente, Almelo, Netherlands

P Department of Pulmonary Diseases, Deventer hospital, Deventer, Netherlands

${ }^{q}$ Department of Pulmonary Diseases, Groene Hart hospital, Gouda, Netherlands
}

\section{A R T I C L E I N F O}

\section{Article history:}

Received 7 April 2015

Received in revised form 22 August 2015

Accepted 13 September 2015

\section{Keywords:}

Non-small cell lung cancer

KRAS mutation

Chemotherapy

Outcome

Type of KRAS mutation

\begin{abstract}
A B S T R A C T
Objectives: As suggested by in-vitro data, we hypothesize that subtypes of KRAS mutated non-small cell lung cancer (NSCLC) respond differently to chemotherapy regimens.

Methods: Patients with advanced NSCLC and known KRAS mutation, treated with first-line platinumbased chemotherapy, were retrieved from hospital databases. Primary objective: to investigate overall response rate (ORR), progression free survival (PFS) and overall survival (OS) between different types of platinum-based chemotherapy per type of KRAS mutation.

Results: 464 patients from 17 hospitals, treated between 2000 and 2013, were included. The majority of patients had stage IV disease (93\%), had a history of smoking (98\%) and known with an adenocarcinoma (91\%). Most common types of KRAS mutation were G12C (46\%), G12V (20\%) and G12D (10\%). Platinum was combined with pemetrexed $(n=334)$, taxanes $(n=68)$ or gemcitabine $(n=62)$. Patients treated with taxanes had a significant improved ORR $(50 \%)$ compared to pemetrexed $(21 \%)$ or gemcitabine $(25 \%$; $p<0.01)$. Patients treated with bevacizumab in addition to taxanes $(n=38)$ had the highest ORR $(62 \%)$. The PFS was significantly improved in patients treated with taxanes compared to pemetrexed $(\mathrm{HR}=0.72$, $p=0.02)$, but not $\mathrm{OS}(\mathrm{HR}=0.87, p=0.41)$. In patients with $\mathrm{G} 12 \mathrm{~V}$, significantly improved $\mathrm{ORR}(p<0.01)$ was observed for taxanes, but not PFS or OS. Patients with G12C or G12D mutation had comparable ORR, PFS and $O S$ in all treatment groups.
\end{abstract}

\footnotetext{
* Corresponding author at: Department of Pulmonary Diseases, VU University Medical Center, PO Box 7057,1007 MB Amsterdam, Netherlands. Fax: +31 20 4444328. E-mail address: ef.smit@vumc.nl (E.F. Smit).
} 
Conclusion: KRAS mutated NSCLC patients treated with taxane-based chemotherapy had best ORR. Response to chemotherapy regimens was different in types of KRAS mutation. Especially patients with G12V had better response to taxane treatment.

(C) 2015 Elsevier Ireland Ltd. All rights reserved.

\section{Introduction}

Personalized medicine has a major role in optimizing treatment and outcome of advanced cancers. Therapy focused on molecular characteristics has taken a substantial part in new treatment strategies for non-small cell lung cancer (NSCLC). Successful treatments have been developed for advanced NSCLC patients with an EGFR mutation or $A L K$ translocation [1,2]. In non-squamous NSCLC, routine testing for these mutations is recommended as per guidelines when patients are no candidates for treatment with curative intent [3]. In the Netherlands, KRAS mutation is part of routine testing as a selection tool for EGFR mutation testing since both mutations are almost allways mutually exclusive [4]. KRAS mutation is observed in $20-30 \%$ of NSCLC patients, predominantly in patients with adenocarcinoma [5]. Its presence has an infamous reputation of quick progression and poor response to chemotherapy [6]. However, the current understanding is that KRAS mutated NSCLC patients have a similar response and survival compared to patients with KRAS wild type (wt) tumors [7-10]. Until now, no effective targeted therapy has been established and standard platinum-based doublet chemotherapy remains the recommended treatment option in this large group of patients.

Alternatively, optimizing treatment for NSCLC patients with a KRAS mutation might also be accomplished by selecting the best chemotherapy for these patients. A KRAS mutation occurs predominantly in codon 12,13 or 61 . Most common types of KRAS mutation are G12C, G12V, and G12D (http://www.mycancergenome.org). In-vitro data generated by Garassino et al. suggested differential sensitivity to chemotherapeutic agents across NSCLC cell lines harboring a G12C, G12V or G12D KRAS mutation [11]. They concluded that the $\mathrm{G} 12 \mathrm{C}$ mutation was most sensitive to pemetrexed and paclitaxel, G12D was resistant to paclitaxel therapy and G12V was slightly less sensitive for pemetrexed. Exposure to gemcitabine resulted in a similar response in the 3 types of mutation. The aim of this multicenter, retrospective study was to investigate differences in overall response rate (ORR), progression free survival (PFS) and overall survival (OS) between subtypes of KRAS mutation in NSCLC patients treated with first-line commonly available platinum doublets.

\section{Methods}

\subsection{Study subjects}

We retrospectively selected all consecutive NSCLC patients with known KRAS mutation, treated with first-line platinumbased chemotherapy for metastatic disease and response evaluated by CT scan using RESIST criteria. Palliative radiotherapy during chemotherapy treatment was allowed. Exclusion criteria were: unknown mutational status; (concurrent) EGFR or ALK mutation; no documentation of response evaluation; adjuvant chemotherapy or chemoradiotherapy.

Patients were derived from databases from 17 hospitals in the Netherlands. All patients had access to the same standard of care treatment. Both regional and academic hospitals participated in this study. The following data were retrieved from the medical records: age, sex, smoking history, World Health Organization Per- formance Status (PS), histology, type of KRAS mutation, stage of disease, site of metastasis, chemotherapy combination, number of courses, response to treatment, type of second line treatment, number of lines of chemotherapy, date of diagnosis, date of start treatment, date of progression and date of death or date of last contact. The ethics committee of the VU University Medical Center Amsterdam approved this study.

\subsection{KRAS mutational screening}

From formalin-fixed paraffin-embedded tissue, tumor was macrodissected and DNA was extracted. Two methods were used for KRAS mutation analysis. In 16/17 hospitals, mutation analysis was performed using high resolution melting followed by polymerase chain reaction and sequencing of the KRAS exons 2 and 3 . At one site mutation analysis was performed by Sanger sequencing only.

\subsection{Statistical analysis}

The primary objective was to evaluate differences in ORR, PFS and OS between different types of platinum-based chemotherapy per type of KRAS mutation. PFS was defined as time from start of first-line chemotherapy till objective disease progression or death; OS was defined as the time from start of treatment till death. The relation between categorical parameters was tested using Pearson's $\mathrm{X}^{2}$-test or Fishers exact test for testing small cell sample sizes $(n \leq 5)$. Kaplan-Meier curve was used to estimate the distribution of survival. Log-rank test was used to test difference in survival between subgroups. To estimate the hazard ratio (HR), cox regression analysis was used. The following variables were considered in a multivariate analysis: age, gender, performance score, histology, smoking history and stage of disease. P-Values $<0.05$ were considered statistically significant.

\section{Results}

\subsection{Patient characteristics}

In total, data from 464 KRAS mutated patients with advanced NSCLC who received palliative platinum-based chemotherapy as first-line treatment were subtracted from databases of 17 hospitals. Patients were treated between 2000 and 2013, most patients (78\%) between 2010 and 2013. Sixty patients in the present study were also part of a previously published study [10].

The patient characteristics are listed in Table 1 . The mean age was 61 years $(S D \pm 9)$, a majority of patients had stage IV disease (93\%), 98\% of the patients had a history of smoking and $2 \%$ of patients had squamous cell carcinoma. Cisplatin $(n=261)$ or carboplatin $(n=203)$ was combined with pemetrexed $(n=334)$, taxane $(n=68)$ or gemcitabine $(n=62)$. In the taxane group, 38 patients received treatment with carboplatin/paclitaxel/bevacizumab (CPB). Codon 12 mutations were detected in $89 \%$ of the patients. G12C (46\%) was the most common KRAS mutation followed by G12V (20\%) and G12D (11\%). Other codon 12 mutations were present in $12 \%$ of the patients. In 1 patient a double mutation was found: G12R+G12S. 
Table 1

Patient characteristics.

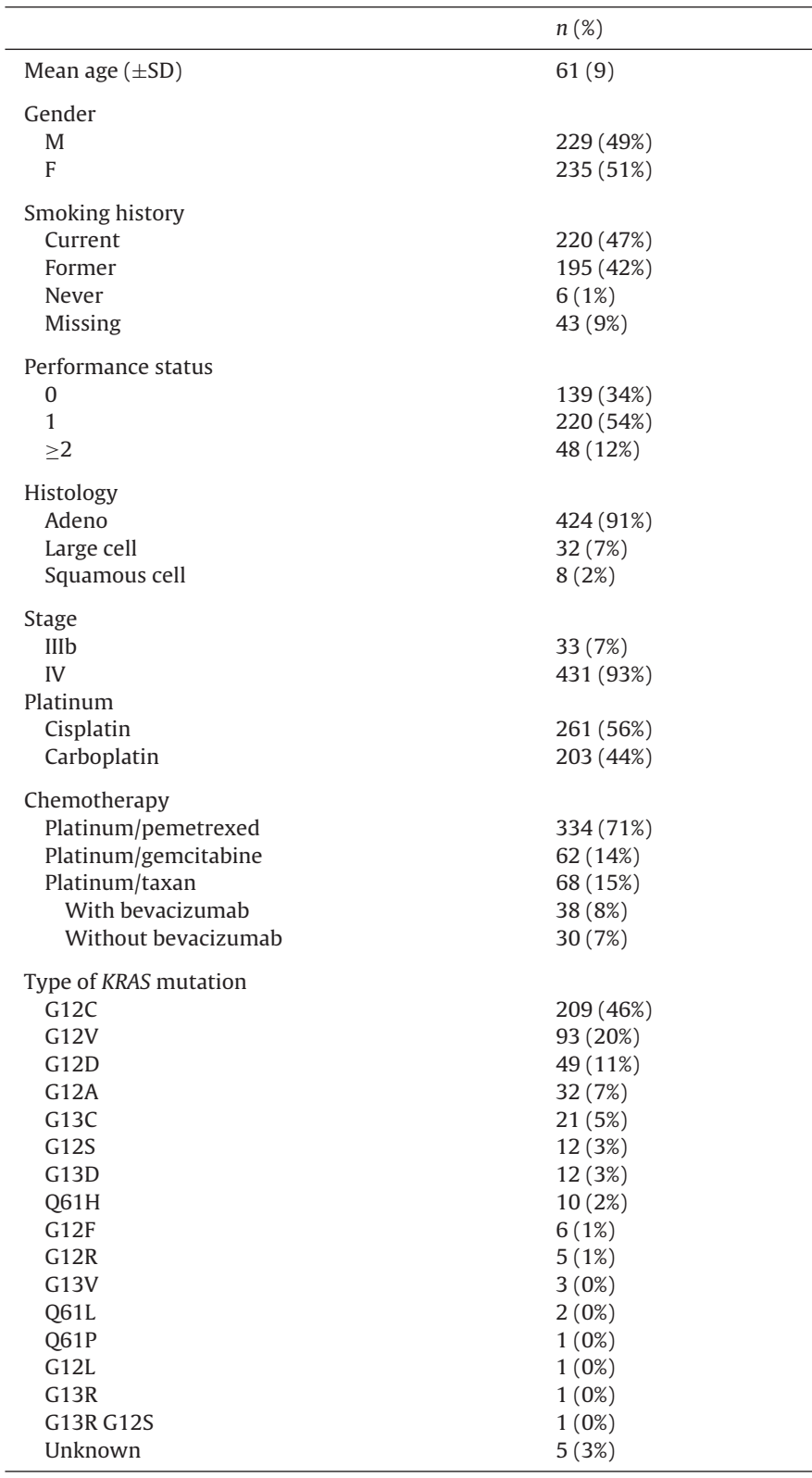

\subsection{Outcome of general study group}

The ORR in the general study group was $26 \%$. Patients treated with taxanes had a significant higher ORR compared to the other platinum combinations (Table 2). In particular, patients treated with CPB had a ORR of 62\%. Fig. 1 demonstrates PFS and OS in the general study group. Patients treated with taxanes had a significantly improved PFS compared to pemetrexed (multivariate $\mathrm{HR}=0.72$ (95\% Cl. 0.54-0.96); $p=0.02$ ), but not OS (multivariate $\mathrm{HR}=0.87$ (95\% CI. 0.63-1.20); $p=0.41$ ). Performance score was the only significant prognostic factor and was considered in the multivariate analysis. No difference was found between patients receiving taxanes only and in addition with bevacizumab in PFS or OS ( $p=0.86$ and $p=0.75$, respectively). The presence of patients with squamous cell carcinoma had no influence on outcome. The one-year survival rate was significantly improved for patients treated with taxanes (41\%), compared to pemetrexed (25\%) or gemcitabine (32\%; $p=0.03)$.
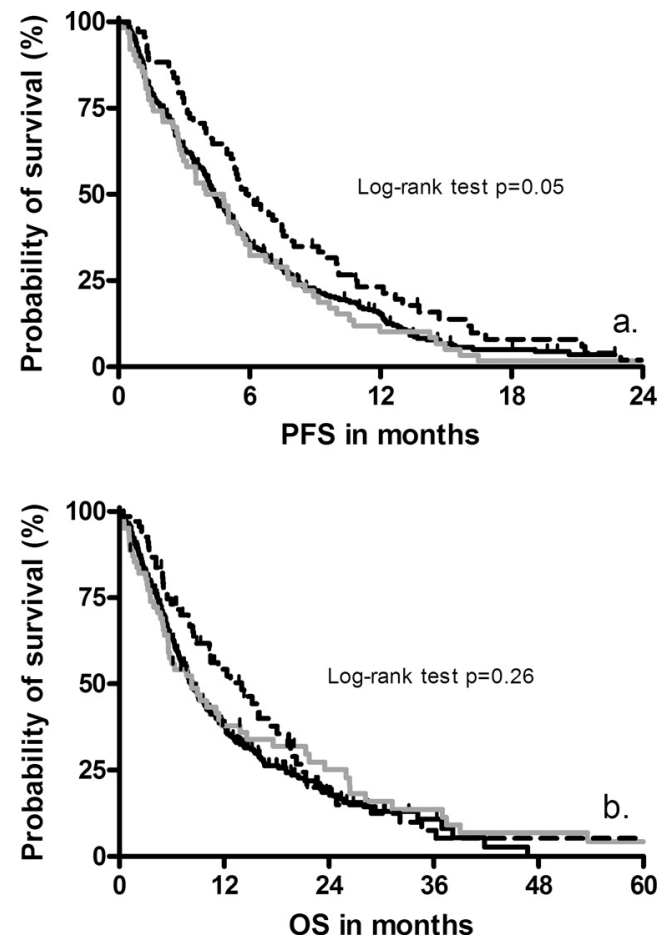

Fig. 1. Outcome in whole study group. Black line: pemetrexed; grey line: gemcitabine; dotted line: taxanes. A. Progression free survival in months. B. Overall survival in months.

\subsection{Outcome of most common types of mutation}

In Tables 2 and 3 results of the 3 most frequent types of KRAS mutation is listed. Patients with G12V mutation had a significantly improved ORR, when treated with taxanes compared to pemetrexed or gemcitabine. For patients with G12V mutation relevant differences were seen in median PFS and OS rates in favor of taxanes, but this was not significant. However, in patients with a G12C or G12D mutation, ORR, PFS and OS were comparable between all treatment groups. Figs. 2 and 3 illustrate PFS and OS respectively per type of mutation.

To study predictive or prognostic relevance of one of the KRAS mutation subtypes, survival plots were made irrespectively of treatment. No significant differences were found in median PFS between the most common types of KRAS mutation: 4.9 (95\% CI, 4.1-5.7) months, 4.8 (95\% CI, 3.0-6.6) months and $4.3(95 \% \mathrm{CI}$, $3.2-5.4$ ) months for G12C, G12V and G12D, respectively ( $p=0.45$ ). Also, no significant differences were found in median OS between the types of mutation: 10.4 (95\% CI, 7.8-13.1) months, 8.0 (95\% CI, 6.4-9.5) months and 8.3 (95\% CI, 7.0-9.5) months, respectively $(p=0.46)$. MedianOS was comparable between codon 12, codon 13 and codon $61(p=0.40)$.

\section{Discussion}

Platinum-based chemotherapy containing a taxane showed the best ORR in this cohort of KRAS mutated advanced NSCLC patients, especially when bevacizumab was added. Taxanes showed significant improved PFS compared to pemetrexed. Patients with a G12V mutation favor treatment with taxanes in terms of response and showed non-significant but clinical relevant changes in survival. In patients with G12C or G12D KRAS mutation all platinum combinations had a similar outcome.

To our knowledge, this is the largest series reporting on therapeutic outcome to first-line platinum-based treatment in KRAS mutated NSCLC patients and first to report preference 
Table 2

Outcome in whole study group and most common types of KRAS mutation.

\begin{tabular}{|c|c|c|c|}
\hline Chemotherapy regimen $(N)$ & ORR & Median PFS in months (95\% CI) & Median OS in months $(95 \% \mathrm{CI})$ \\
\hline \multicolumn{4}{|l|}{ Whole group } \\
\hline PEM & $21 \%$ & $4.3(3.8-4.8)$ & $8.2(7.0-9.4)$ \\
\hline GEM (62) & $25 \%$ & $4.0(2.7-5.3)$ & $8.3(4.2-12.3)$ \\
\hline \multirow[t]{2}{*}{ TAX (68) } & $50 \%$ & $5.8(4.4-7.3)$ & $14.0(9.0-19.0)$ \\
\hline & $p<0.01$ & Log-rank test $p=0.05$ & Log-rank test $p=0.26$ \\
\hline \multicolumn{4}{|l|}{ G12C } \\
\hline $\operatorname{PEM}(145)$ & $23 \%(16-30)$ & $4.5(3.7-5.3)$ & $9.9(7.2-12.7)$ \\
\hline GEM (32) & $32 \%(15-50)$ & $3.9(1.3-6.6)$ & $10.0(4.9-15.1)$ \\
\hline \multirow[t]{2}{*}{$\operatorname{TAX}(31)$} & $40 \%(21-59)$ & $5.4(3.6-7.1)$ & $12.3(8.2-16.4)$ \\
\hline & $p=0.12$ & Log-rank test $p=0.42$ & Log-rank test $p=0.50$ \\
\hline \multicolumn{4}{|l|}{ G12V } \\
\hline PEM (67) & $17 \%(8-27)$ & $4.2(2.5-5.9)$ & $7.0(4.7-9.3)$ \\
\hline GEM (11) & $18 \%(9-45)$ & $3.0(1.8-4.1)$ & $5.6(0.0-19.7)$ \\
\hline \multirow[t]{2}{*}{ TAX (12) } & $67 \%(35-98)$ & $6.9(0.0-13.9)$ & $19.4(15.3-23.6)$ \\
\hline & $p<0.01$ & Log-rank test $p=0.09$ & Log-rank test $p=0.20$ \\
\hline \multicolumn{4}{|l|}{ G12D } \\
\hline PEM (37) & $16 \%(2-29)$ & $4.1(2.7-5.4)$ & $7.5(4.5-10.4)$ \\
\hline GEM (6) & $17 \%(26-60)$ & $5.0(3.4-6.7)$ & $8.3(6.0-10.6)$ \\
\hline \multirow[t]{2}{*}{$\operatorname{TAX}(6)$} & $50 \%(7-107)$ & $5.8(1.4-10.3)$ & $8.5(0.9-16.0)$ \\
\hline & $p=0.16$ & Log-rank test $p=0.58$ & Log-rank test $p=0.89$ \\
\hline
\end{tabular}

Abbreviations: PEM: pemetrexed; GEM: gemcitabine; TAX: taxane; PFS: progression free survival; OS: overall survival; CI: confidence interval.

Table 3

Univariate regression analysis of progression free survival and overall survival.

\begin{tabular}{|c|c|c|c|c|c|c|}
\hline \multirow[t]{2}{*}{ Chemotherapy regimen $(\mathrm{N})$} & \multicolumn{3}{|c|}{ Median PFS in months $(95 \% \mathrm{CI})$} & \multicolumn{3}{|c|}{ Median OS in months $(95 \% \mathrm{CI})$} \\
\hline & $\mathrm{HR}$ & $95 \%$ CI. & $p$-Value & HR & $95 \% \mathrm{CI}$. & $p$-Value \\
\hline \multicolumn{7}{|l|}{ Whole group } \\
\hline PEM (334) & 1.00 & - & & 1.00 & - & \\
\hline GEM (62) & 1.07 & $0.81-1.42$ & 0.62 & 0.90 & $0.66-1.22$ & 0.48 \\
\hline $\operatorname{TAX}(68)$ & 0.73 & $0.55-0.96$ & 0.03 & 0.78 & $0.58-1.06$ & 0.11 \\
\hline \multicolumn{7}{|l|}{ G12C } \\
\hline PEM (145) & 1.00 & - & & 1.00 & - & \\
\hline GEM (32) & 0.84 & $0.56-1.35$ & 0.39 & 0.72 & $0.45-1.15$ & 0.17 \\
\hline $\operatorname{TAX}(31)$ & 0.88 & $0.59-1.31$ & 0.54 & 0.94 & $0.60-1.47$ & 0.78 \\
\hline \multicolumn{7}{|l|}{ G12V } \\
\hline $\operatorname{PEM}(67)$ & 1.00 & - & & 1.00 & - & \\
\hline GEM (11) & 1.58 & $0.82-3.03$ & 0.17 & 0.92 & $0.45-1.9$ & 0.82 \\
\hline $\operatorname{TAX}(12)$ & 0.64 & $0.35-1.18$ & 0.15 & 0.54 & $0.28-1.07$ & 0.08 \\
\hline \multicolumn{7}{|l|}{ G12D } \\
\hline PEM (37) & 1.00 & - & & 1.00 & - & \\
\hline GEM (6) & 0.94 & $0.39-2.27$ & 0.90 & 1.22 & $0.46-3.21$ & 0.69 \\
\hline $\operatorname{TAX}(6)$ & 0.61 & $0.24-1.57$ & 0.31 & 0.88 & $0.33-2.30$ & 0.79 \\
\hline
\end{tabular}

Abbreviations: PEM: pemetrexed; GEM: gemcitabine; TAX: taxane; PFS: progression free survival; OS: overall survival; HR: hazard ratio; CI: confidence interval.

for chemotherapy. Previously it has been described that NSCLC patients with a KRAS mutation may have a significantly lower ORR to treatment with either pemetrexed or gemcitabine compared to KRAS wt patients [12]. In the same study it was found that the presence of a KRAS mutation is both a poor predictive and prognostic biomarker. However, this study comprised a small group of KRAS mutated NSCLC $(n=39)$ only. Other studies in patients with advanced NSCLC report no difference in clinical outcome after chemotherapeutic treatment by KRAS mutational status [8-10]. In a preclinical study, Garassino et al. demonstrated differences in response to chemotherapeutic regimens per type of KRAS mutation in lung cancer cell lines. Pemetrexed was most effective in G12C, but less in G12D or G12V [11]. Gemcitabine had a similar response in all 3 types and paclitaxel showed best response in G12C and G12V but less in G12D. In our retrospective analysis we could not confirm the sensitivity of the types of KRAS mutation to the respective regimens. However, we did find differences in sensitivity between types of KRAS mutation that support the hypothesis that drug sensitivity may differ depending on the type of KRAS mutation.
To our knowledge, KRAS mutation has not been linked previously to taxane sensitivity. Increased sensitivity to taxane in NSCLC patients with a KRAS mutation may be explained by the role in mitosis of downstream effectors of KRAS [13]. Taxanes stabilizes microtubules during mitosis, resulting in apoptosis of the dividing cell. It has been described that activated ERK, downstream of $K R A S$, has an important role in regulation of the stabilization of microtubules [14]. It has also been reported that apoptosis induced by paclitaxel is dependent on activation of the MAP kinases [15]. One may hypothesize that continuous activation of the MAPK pathway due to a KRAS mutation may therefore lead to sensitivity to taxane. The addition of bevacizumab to taxane resulted in highest response rate in our group of patients. Bevacizumab is a monoclonal antibody targeting vascular endothelial growth factor (VEGF), a pro-angiogenetic factor that may play a role in tumor progression and metastasis [16,17]. Bevacizumab induces inhibition of new tumor vasculature, regression of existing tumor microvasculature and normalization of remaining tumor vasculature [18]. Increased VEGF expression has been observed in KRAS mutated NSCLC $[19,20]$. This may influence the response to VEGF targeted 

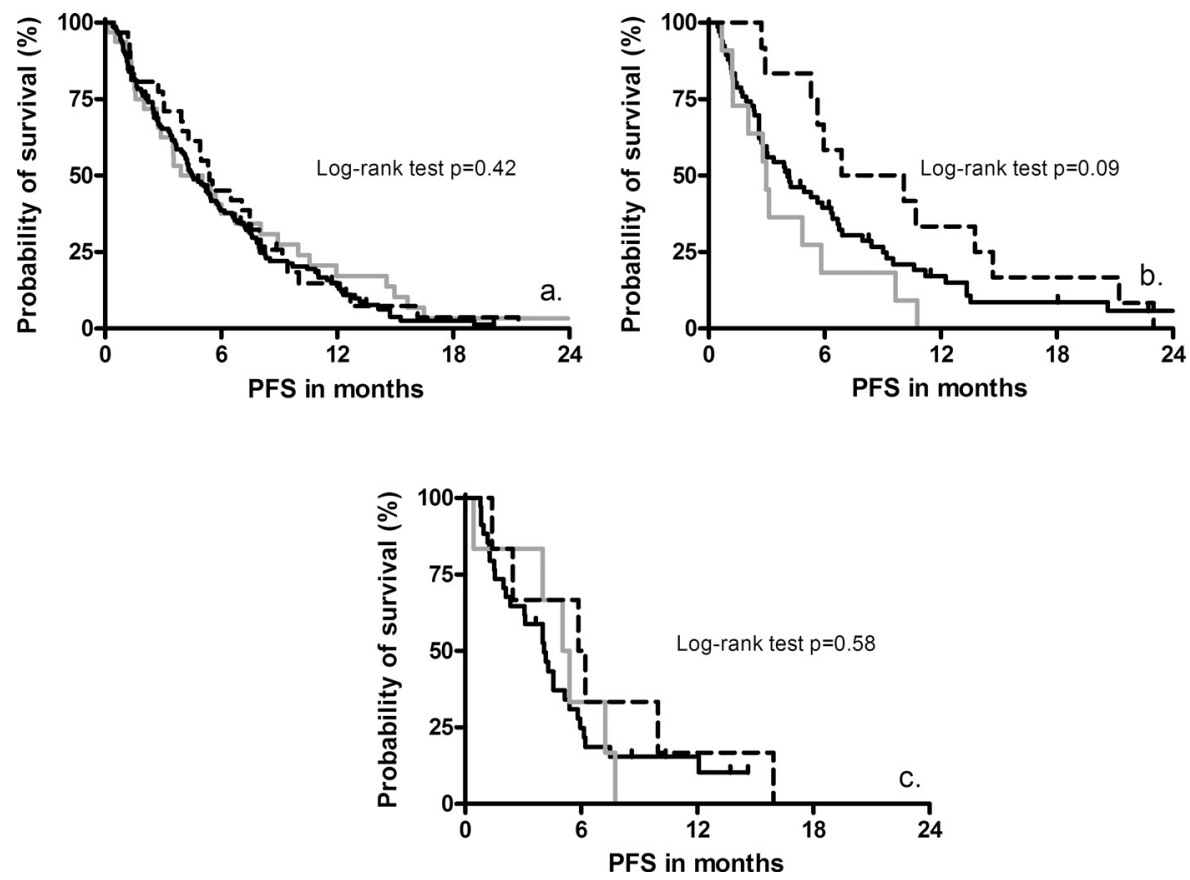

Fig. 2. Comparison of progression free survival (PFS) of chemotherapy regimens per most common types of KRAS mutation. Black line: pemetrexed; grey line: gemcitabine; dotted line: taxanes. A. PFS in months of patients with G12C; B. PFS in months of patients with G12V; C. PFS in months of patients with G12D.
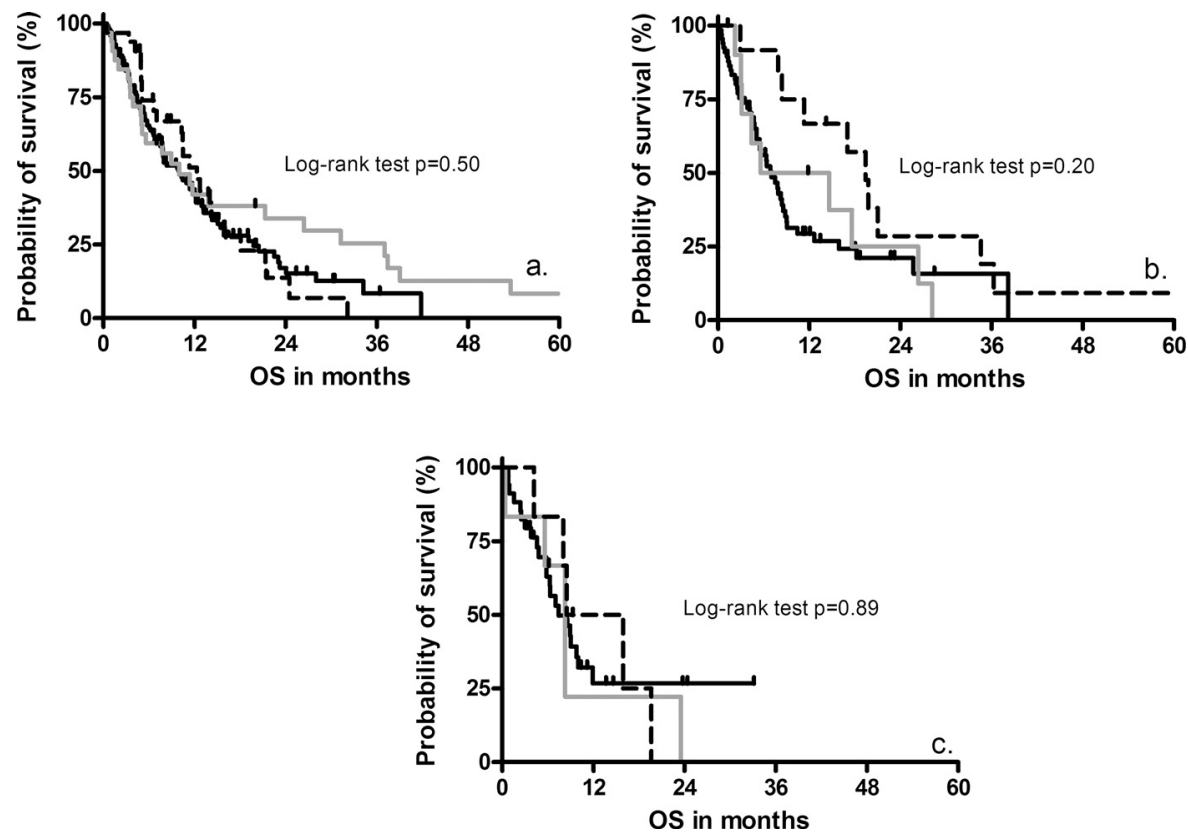

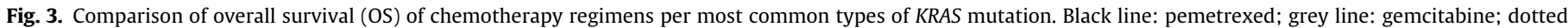
line: taxanes. A. OS in months of patients with G12C; B. OS in months of patients with G12V; C. OS in months of patients with G12D.

therapy. Although our observations are not substantiated by preclinical evidence, it is hypothesis generating, and can easily been studied in prospective clinical trials.

There is a great demand for effective treatment strategies in KRAS mutant cancer. Despite numerous attempts, direct inhibition of mutated RAS protein has not been successful and is believed to be undruggable. The first success in targeting downstream effectors of KRAS in NSCLC is reported by Janne et al. In a randomized, placebo-controlled phase II trail, NSCLC patients with advanced disease harboring a KRAS mutation and failed first-line treatment were randomized between selumetinib and docetaxel or docetaxel and placebo. Median OS camparable in the selumetinib group and placebo group (9.4 months versus 5.2 months, $p=0.21$ ). However, PFS and ORR were significantly improved [23]. A phase III study is now enrolling patients. Encouraging data is published on a shutdown of KRAS-G12C variant by selective and irreversible binding of a designed small molecule [24]. Other types of KRAS mutation or KRAS wt could not be shut down by the compound. This could be an important step toward targeted treatment of KRAS mutated cancer. Further development of the compound for clinical testing is in progress. 
Our study has some limitations. First, this study has heterogeneity in treatment regimens and treatment decisions, because of many participating hospitals. Also, response was not centrally reviewed, which may produce a bias in the estimation of response. Because of its retrospective nature and selection, this patient study group may not be representative. Firm conclusions cannot be drawn based on our data, among others because of the small sample size in subgroups. However, we provide some evidence and give rationale that KRAS genotyping could be considered for selecting patients for treatment with platinum combined with taxanes.

Ihle et al. suggested that there is a difference in behavior of different types of KRAS mutation, due to activation of different downstream growth signaling pathways [22]. In this preclinical study, using mutant KRAS-transfected NSCLC cell lines, it was found that $\mathrm{G} 12 \mathrm{C}$ mutation had a downstream stimulation of RAF and RAL, but G12D stimulation of RAF and AKT. Further research is needed on the biology and signaling of different types of KRAS mutation, to improve understanding of the differential effect of chemotherapy on distinct KRAS mutations and develop more effective (targeted) treatments.

In conclusion, taxane-based chemotherapy showed significantly improved ORR and prolonged PFS compared to other platinum-containing regimens in the whole study group. Response to first-line platinum-based chemotherapy was dissimilar in different types of KRAS mutated NSCLC patients. Especially G12V had better response to taxane treatment. More understanding on tumor biology of KRAS mutated NSCLC and its subtypes is urgently needed. Further, we encourage study of taxane-based chemotherapy in advanced NSCLC patients with a KRAS mutation in randomized control trials.

\section{Financial support and conflict of interest}

All authors state they have no financial supports or conflict of interest.

\section{Acknowledgements}

We thank the following contributors for providing data: Willemijn Engelsman-Theelen, Mark de Mol, Anneke Horstman, Jeroen Hilterman, Clemens Prinsen, Nils't Hart.

\section{References}

[1] J.Y. Douillard, F.A. Shepherd, V. Hirsh, T. Mok, M.A. Socinski, R. Gervais, et al., Molecular predictors of outcome with gefitinib and docetaxel in previously treated non-small-cell lung cancer: data from the randomized phase III INTEREST trial, J. Clin. Oncol. 28 (February (5)) (2010) 744-752.

[2] A.T. Shaw, D.W. Kim, K. Nakagawa, T. Seto, L. Crino, M.J. Ahn, et al., Crizotinib versus chemotherapy in advanced ALK-positive lung cancer, N. Engl. J. Med. 368 (25) (2013 Jun 20) 2385-2394.

[3] D.S. Ettinger, W. Akerley, H. Borghaei, A.C. Chang, R.T. Cheney, L.R. Chirieac, et al., Non-small cell lung cancer, version 2, J. Natl. Compr. Cancer Netw. 11 (June (6)) (2013) 645-653.

[4] T. Kosaka, Y. Yatabe, H. Endoh, H. Kuwano, T. Takahashi, T. Mitsudomi, Mutations of the epidermal growth factor receptor gene in lung cancer: biological and clinical implications, Cancer Res. 64 (December (24)) (2004) 8919-8923.
[5] S. Rodenhuis, R.J. Slebos, A.J. Boot, S.G. Evers, W.J. Mooi, S.S. Wagenaar, et al., Incidence and possible clinical significance of K-ras oncogene activation in adenocarcinoma of the human lung, Cancer Res. 48 (October (20)) (1988) 5738-5741.

[6] R.J. Slebos, R.E. Kibbelaar, O. Dalesio, A. Kooistra, J. Stam, C.J. Meijer, et al., K-ras oncogene activation as a prognostic marker in adenocarcinoma of the lung, N. Engl. J. Med. 323 (August (9)) (1990) 561-565.

[7] S. Rodenhuis, L. Boerrigter, B. Top, R.J. Slebos, W.J. Mooi, L. van't Veer, et al., Mutational activation of the K-ras oncogene and the effect of chemotherapy in advanced adenocarcinoma of the lung: a prospective study, J. Clin. Oncol. 15 (January (1)) (1997) 285-291.

[8] D.A. Eberhard, B.E. Johnson, L.C. Amler, A.D. Goddard, S.L. Heldens, R.S. Herbst, et al., Mutations in the epidermal growth factor receptor and in KRAS are predictive and prognostic indicators in patients with non-small-cell lung cancer treated with chemotherapy alone and in combination with erlotinib, J Clin. Oncol. 23 (September (25)) (2005) 5900-5909.

[9] A. Kalikaki, A. Koutsopoulos, D. Hatzidaki, M. Trypaki, E. Kontopodis, E. Stathopoulos, et al., Clinical outcome of patients with non-small cell lung cancer receiving front-line chemotherapy according to EGFR and K-RAS mutation status, Lung Cancer (Amsterdam, Netherlands) 69 (July (1)) (2010) 110-115.

[10] W.W. Mellema, A.M. Dingemans, E. Thunnissen, P.J. Snijders, J. Derks, D.A Heideman, et al., KRAS mutations in advanced nonsquamous non-small-cell lung cancer patients treated with first-line platinum-based chemotherapy have no predictive value, J. Thorac. Oncol. 8 (September (9)) (2013) 1190-1195

[11] M.C. Garassino, M. Marabese, P. Rusconi, E. Rulli, O. Martelli, G. Farina, et al. Different types of K-Ras mutations could affect drug sensitivity and tumour behaviour in non-small-cell lung cancer, Ann. Oncol. 22 (January (1)) (2011) 235-237.

[12] J.M. Sun, D.W. Hwang, J.S. Ahn, M.J. Ahn, K. Park, Prognostic and predictive value of KRAS mutations in advanced non-small cell lung cancer, PLoS One 8 (5) (2013) e64816.

[13] X. Liu, S. Yan, T. Zhou, Y. Terada, R.L. Erikson, M.A.P. The, Kinase pathway is required for entry into mitosis and cell survival, Oncogene 23 (January (3)) (2004) 763-776

[14] R.E. Harrison, E.A. Turley, Active erk regulates microtubule stability in H-ras-transformed cells, Neoplasia (New York, NY) 5 (September-October (5)) (2001) 385-394

[15] S.S. Bacus, A.V. Gudkov, M. Lowe, L. Lyass, Y. Yung, A.P. Komarov, et al., Taxol-induced apoptosis depends on MAP kinase pathways (ERK and p38) and is independent of p53, Oncogene 20 (January (2)) (2001) 147-155.

[16] N. Ferrara, Vascular endothelial growth factor: basic science and clinical progress, Endocr. Rev. 25 (August (4)) (2004) 581-611.

[17] D.J. Hicklin, L.M. Ellis, Role of the vascular endothelial growth factor pathway in tumor growth and angiogenesis, J. Clin. Oncol. 23 (February (5)) (2005) $1011-1027$.

[18] L.M. Ellis, D.J. Hicklin, VEGF-targeted therapy: mechanisms of anti-tumour activity, Nat. Rev. 8 (August (8)) (2008) 579-591.

[19] T. Konishi, C.L. Huang, M. Adachi, T. Taki, H. Inufusa, K. Kodama, et al., The $\mathrm{K}-\mathrm{ras}$ gene regulates vascular endothelial growth factor gene expression in non-small cell lung cancers, Int. J. Oncol. 16 (March (3)) (2000) 501-511.

[20] N. Ikeda, Y. Nakajima, M. Sho, M. Adachi, C.L. Huang, K. Iki, et al., The association of K-ras gene mutation and vascular endothelial growth factor gene expression in pancreatic carcinoma, Cancer 92 (August (3)) (2001) 488-499.

[22] N.T. Ihle, L.A. Byers, E.S. Kim, P. Saintigny, J.J. Lee, G.R. Blumenschein, et al., Effect of KRAS oncogene substitutions on protein behavior: implications for signaling and clinical outcome, J. Natl. Cancer Inst. 104 (February (3)) (2011) 228-239.

[23] P.A. Janne, A.T. Shaw, J.R. Pereira, G. Jeannin, J. Vansteenkiste, C. Barrios, et al., Selumetinib plus docetaxel for KRAS-mutant advanced non-small-cell lung cancer: a randomised, multicentre, placebo-controlled, phase 2 study, Lancet 14 (January (1)) (2013) 38-47

[24] J.M. Ostrem, U. Peters, M.L. Sos, J.A. Wells, K.M. Shokat, K-Ras(G12C) inhibitors allosterically control GTP affinity and effector interactions, Nature 503 (November (7477)) (2013) 548-551 